\title{
A Community of Practice for Teaching the Social Determinants of Health in Undergraduate Medical Education
}

\author{
Ashti Doobay-Persaud, $M D^{1,2}$ (D, Mark D. Adler, MD ${ }^{3,4}$, Tami R. Bartell, MPH ${ }^{5}$, \\ Natalie E. Sheneman, BA ${ }^{2}$, Mayra D. Martinez $z^{6}$ Karen A. Mangold, MD, MEd ${ }^{3,4}$, and \\ Karen $M$. Sheehan, MD, $\mathrm{MPH}^{3}$
}

'Division of Hospital Medicine, Department of Medicine, Feinberg School of Medicine, Northwestern University, Chicago, IL, USA; ${ }^{2}$ Institute for Global Health, Feinberg School of Medicine, Northwestern University, Chicago, IL, USA; ${ }^{3}$ Department of Pediatrics, Feinberg School of Medicine, Northwestern University, Chicago, IL, USA; ${ }^{4}$ Department of Medical Education, Feinberg School of Medicine, Northwestern University, Chicago, IL, USA; ${ }^{5}$ Mary Ann \& J. Millburn Smith Child Health Research, Outreach and Advocacy Center, Stanley Manne Children's Research Institute, Ann \& Robert H. Lurie Children's Hospital of Chicago, Chicago, IL, USA; 'Loyola University Chicago, Chicago, IL, USA.

J Gen Intern Med 35(4):1315-6

DOI: $10.1007 / \mathrm{s} 11606-019-05288-\mathrm{w}$

(c) Society of General Internal Medicine 2019

$\mathrm{D}$ ear Editor,

We are very appreciative of the enthusiastic response to our article, "Teaching the Social Determinants of Health in Undergraduate Medical Education: A Scoping Review," "and thank Drs. Abbie Dunn and Scott Mackenzie for sharing their knowledge and experience with implementing a multifaceted and longitudinal curriculum at their own institution. ${ }^{2}$

While we were careful not to overstate the implications of our review - in recognition that our findings were limited to published programs and research — we also believe that publication can be reflective of the maturity of a field and the priorities of the organizations to which practitioners belong. In other words, if educators are provided with the resources to not only run their programs well but also rigorously assess and benchmark them against peer institutions, then they are more likely to disseminate these practices through publication than those who do not receive such support. In this way, the published literature on teaching the social determinants of health (SDH) tells the story of how certain medical schools have elevated these issues, or in other cases, failed to do so. These choices affect the academic quality of SDH teaching overall.

Critical to the continuous growth and improvement in this field is the ability to share curricular innovation and best practices, at any stage from design to evaluation, in venues outside of medical journals. At Northwestern University's Feinberg School of Medicine, we are honored to be members of the US-based

Received August 5, 2019

Revised August 5, 2019

Accepted August 8, 2019

Published online August 26, 2019
National Collaborative for Education to Address the Social Determinants of Health (NCEAS). ${ }^{3}$ NCEAS is a resource library, research and policy think tank, and community of practice - all supporting the proliferation of SDH education, scholarship, and healthcare approaches developing across the country and around the world. Specifically, the NCEAS education collection invites submissions of detailed curricula, like the one that Drs. Dunn and Mackenzie describe. ${ }^{4}$ This collection aims to serve as a repository of resources for fellow educators to use when training learners about social and structural determinants of health. We welcome other passionate educators and healthcare providers to submit to the education collection, join the NCEAS network, and work collectively to promote SDH education in research and practice.

Sincerely,

Ashti Doobay-Persaud, MD, Northwestern University Feinberg School of Medicine

Mark D. Adler, MD, Northwestern University Feinberg School of Medicine

Tami R. Bartell, MPH, Northwestern University Feinberg School of Medicine

Natalie E. Sheneman, Northwestern University Feinberg School of Medicine

Mayra D. Martinez, Loyola University Chicago

Karen A. Mangold, MD, MEd, Northwestern University Feinberg School of Medicine

Karen M. Sheehan, MD, MPH, Northwestern University Feinberg School of Medicine

Corresponding Author: Ashti Doobay-Persaud, MD; Institute for Global HealthFeinberg School of Medicine, Northwestern University, Chicago, IL, USA (e-mail: a-doobay-persaud@northwestern.edu).
Funding Information The NCEAS is supported by the Health Resources and Services Administration (HRSA) of the US Department of Health and Human Services (HHS) under grant number UH1HP29963, Academic Units for Primary Care Training and Enhancement. This information or content and conclusions are those 
of the author and should not be construed as the official position or policy of nor should any endorsements be inferred by HRSA, HHS, or the US Government.

\section{Compliance with Ethical Standards:}

Conflict of Interest: The authors declare that they do not have a conflict of interest.

\section{REFERENCES}

1. Doobay-Persaud A, Adler MD, Bartell TR, Sheneman NE, Martinez MD, Mangold KA, Smith P, Sheehan KM. Teaching the Social Determinants of
Health in Undergraduate Medical Education: A Scoping Review. Journal of General Internal Medicine. 2019 May 15;34(5):720-30.

2. Dunn A, Mackenzie SC. Scottish Medical Student Experience of Learning About Social Determinants of Health. Journal of General Internal Medicine. Forthcoming 2019.

3. National Collaborative for Education to Address the Social Determinants of Health. https://sdoheducation.org (accessed 30 June 2019).

4. National Collaborative for Education to Address the Social Determinants of Health. Education Collection. https://sdoheducation.org/about-thenceas-education-collection/ (accessed 30 June 2019).

Publisher's Note Springer Nature remains neutral with regard to jurisdictional claims in published maps and institutional affiliations. 